University of Nebraska - Lincoln

DigitalCommons@University of Nebraska - Lincoln

Papers in Plant Pathology

Plant Pathology Department

2001

\title{
The Aspergillus nidulans snt Genes Are Required for the Regulation of Septum Formation and Cell Cycle Checkpoints
}

Peter R. Kraus

University of Connecticut Health Center

Steven D. Harris

University of Nebraska-Lincoln, Steven.Harris@umanitoba.ca

Follow this and additional works at: https://digitalcommons.unl.edu/plantpathpapers

Part of the Other Plant Sciences Commons, Plant Biology Commons, and the Plant Pathology Commons

Kraus, Peter R. and Harris, Steven D., "The Aspergillus nidulans snt Genes Are Required for the Regulation of Septum Formation and Cell Cycle Checkpoints" (2001). Papers in Plant Pathology. 410.

https://digitalcommons.unl.edu/plantpathpapers/410

This Article is brought to you for free and open access by the Plant Pathology Department at DigitalCommons@University of Nebraska - Lincoln. It has been accepted for inclusion in Papers in Plant Pathology by an authorized administrator of DigitalCommons@University of Nebraska - Lincoln. 


\title{
The Aspergillus nidulans snt Genes Are Required for the Regulation of Septum Formation and Cell Cycle Checkpoints
}

\author{
Peter R. Kraus ${ }^{1}$ and Steven D. Harris \\ Department of Microbiology, University of Connecticut Health Center, Farmington, Connecticut 06030-3205 \\ Manuscript received February 13, 2001 \\ Accepted for publication July 2, 2001
}

\begin{abstract}
In Aspergillus nidulans, germinating conidia undergo multiple rounds of nuclear division before forming a septum. Previous genetic results suggest that the ability to separate nuclear division and septum formation depends upon a threshold level of activity of the cyclin-dependent kinase NIMX ${ }^{\text {cdk1 }}$. Mutations in $\operatorname{nimX}$ and

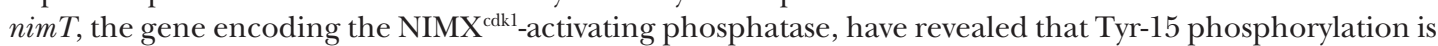
important for determining the timing of the formation of the first septum. Here, we describe a screen for suppressors of nimT23 (snt), designed to identify additional components of the pathway regulating septum formation. We show that a subset of the snt mutants are defective in the temporal regulation of septum formation and in cell cycle checkpoint responses. Molecular characterization of $5 n t A$ shows that it is allelic to the previously described ankA gene, which encodes the NIMX ${ }^{\text {cdk1 }}$ Tyr-15 kinase. Additional experiments described in this study show that nutritional conditions modulate the timing of septum formation and alter the phenotypes displayed by the snt mutants. A model that suggests that the timing of septum formation is influenced by DNA damage and glucose availability via the $s n t A$ and $s n t B$ gene products is proposed.
\end{abstract}

$\mathrm{T}$ HE coordination of cytokinesis with growth and nuclear division is essential for the proper development of all eukaryotic organisms. Mechanisms for ensuring that cytokinesis is coordinated with growth and nuclear division have been described in complex eukaryotes such as Drosophila (reviewed in Neufeld and Edgar 1998) and also in the simple eukaryotes Saccharomyces cerevisiae (reviewed in LEw 2000) and Schizosaccharomyces pombe (reviewed in Cerutti and Simanis 2000). A common feature of these mechanisms is the regulation of the cell cycle machinery, including modulating the activity of cyclindependent kinases. The coordination of cytokinesis with nuclear division represents a unique problem in filamentous fungi such as Aspergillus nidulans. Following spore germination, hyphal cells will undergo several rounds of nuclear division prior to septum formation (HARRIS et al. 1994). Previous results have shown that septum formation is delayed in these cells until a size control is satisfied and a subsequent nuclear division occurs (WoLkow et $a l$. 1996). The cyclin-dependent kinase (cdk) NIMX ${ }^{\text {cdk1 } 1}$ is required for both mitosis and septum formation in $A$. nidulans, yet the ability of predivisional cells (germlings that have not yet formed septa; HARRIs 1997) to undergo mitosis in the absence of septum formation suggests that these effects are separable (HARris and Kraus 1998).

Corresponding author: Steven Harris, Plant Science Initiative, University of Nebraska, The Beadle Center N234, Lincoln, NE 68588-0660. E-mail: sharri1@unlnotes.unl.edu

${ }^{1}$ Present address: Department of Genetics, Duke University Medical Center, Durham, NC 27710.
Genetic evidence suggests that the ability to separate mitosis and septum formation depends upon a threshold level of NIMX ${ }^{\text {cdk1 }}$ activity (HARrIS and Kraus 1998). Specifically, levels of NIMX ${ }^{\text {cdk1 }}$ activity may be assessed at a defined point during the cell cycle of predivisional cells. Only if activity exceeds the threshold does septation occur following the subsequent round of mitosis. This model is supported by the observation that inhibition of cdk activity by activation of the DNA damage checkpoint results in a delay in septum formation (HARRIs and Kraus 1998).

Activation of cdks is controlled by the phosphorylation of specific amino acid residues. The most extensively characterized mechanism of mitotic regulation is the inhibitory phosphorylation of the fission yeast cdk Cdc2p on Tyr-15 (Russell and Nurse 1986, 1987; Gould and Nurse 1989). This phosphorylation is catalyzed by the Weelp and Mik $1 p$ tyrosine kinases and is removed by the tyrosine phosphatase Cdc25p (Millar et al. 1991; McGowan and Russell 1993; LeE et al. 1994). The timing of activation of Cdc2p, a requirement for mitotic entry, is determined by the relative activities of the inhibitory Wee1p/Mik1p pathway and the activating Cdc25p pathway. The activity of the DNA damage and the replication checkpoint pathways of fission yeast are also regulated by inhibitory phosphorylation of Cdc2p (RHIND et al. 1997; ZeNG et al. 1998). In the filamentous fungus $A$. nidulans, mitotic entry is regulated in a similar fashion. The activation of NIMX ${ }^{\text {cdk1 }}$, the A. nidulans ortholog of fission yeast Cdc2p, is required for mitotic entry (Osmani et al. 1991). Inhibitory phosphorylation on Tyr-15 of NIMX ${ }^{\text {cdk1 }}$ is catalyzed by the tyrosine kinase ANKA and removed by the tyrosine phospha- 
tase NIMT, both of which are orthologs of fission yeast Wee1p and Cdc25p, respectively (O'ConNELL et al. 1992; YE et al. 1997). As in fission yeast, the DNA damage checkpoint is regulated by Tyr-15 phosphorylation of NIMX ${ }^{\text {cdk1 }}$ (YE et al. 1997).

One prediction of the threshold model of regulating septum formation is that cdk activity would be inhibited at some point during the predivisional cell cycle. A possible mechanism for preventing NIMX ${ }^{\mathrm{cdk} 1}$ activity from exceeding the threshold level required to initiate septum formation is to regulate NIMT activation. This possibility was investigated by screening for suppressors of the heatsensitive (Ts) nimT23 mutant to identify potential negative regulators of NIMT. Here, we describe the isolation and characterization of mutants that suppress the nimT23 growth defect. As expected, the subset of mutants we chose to analyze displayed defects in the regulation of septum formation. Molecular characterization of one of the genes identified in this screen revealed that it encodes the Weelp tyrosine kinase ortholog ANKA. We also provide evidence that the timing of septum formation is modulated by nutrient availability and that growth conditions can also affect checkpoint responses. On the basis of our results, we propose a model for the regulation of septum formation in A. nidulans.

\section{MATERIALS AND METHODS}

Strains and growth conditions: All strains used in this study are listed in Table 1. Media used were YGV (2\% glucose, $0.5 \%$ yeast extract, $0.01 \%$ vitamins), MNV ( $1 \%$ glucose, nitrate salts, trace elements, and $0.01 \%$ vitamins), MNV-EtOH (MNV with $20 \mathrm{ml} /$ liter ethanol as the only carbon source), MNV-glycerol (MNV with $10 \mathrm{ml} /$ liter glycerol as the only carbon source), MNVOAc (MNV with $100 \mathrm{~mm}$ acetate as the only carbon source), and $\mathrm{CM}(1 \%$ glucose, $0.1 \%$ yeast extract, $0.2 \%$ peptone, $0.1 \%$ casamino acids, nitrate salts, trace elements, and $0.01 \%$ vitamins, $\mathrm{pH}$ 6.5). Nitrate salts, trace elements, and vitamins are described in the appendix to KAFER (1977). Strains carrying the $\operatorname{argB2}$ mutation were supplemented with $0.02 \%$ arginine. Strains carrying the pyrG89 mutation were grown in MAG (2\% malt extract, $2 \%$ glucose, $0.2 \%$ peptone, trace elements, and vitamins) supplemented with $5 \mathrm{~mm}$ uridine and $10 \mathrm{~mm}$ uracil. For solid media, $1.5 \%$ agar was added. Hydroxyurea (HU; Sigma Chemical, St. Louis) was prepared as a $2 \mathrm{M}$ stock solution and added to media after autoclaving. Wild-type strains were incubated at $28^{\circ}$ or $32^{\circ}$, and Ts strains were incubated at $42^{\circ}$ or $43.5^{\circ}$. Diepoxyoctane (DEO; Aldrich Chemical, Milwaukee) was added to liquid media at the time of inoculation at a concentration of $0.025 \%$. 5-Fluoroorotic acid (5-FOA; U.S. Biological) and 3-amino-1,2,4-triazole (3AT; Sigma Chemical) were added to solid media after autoclaving at concentrations of $1 \mathrm{mg} / \mathrm{ml}$ and $0.5 \mathrm{~mm}$, respectively.

Mutagenesis and isolation of snt mutations: A suspension of $10^{6}$ conidia from the strain MO73 was plated on CM plates and irradiated with UV, such that the survival rate was $10 \%$. The plates were incubated for 3 days at the nonpermissive temperature of $43.5^{\circ}$. Colonies that formed were patched in grids on master $\mathrm{CM}$ plates and incubated at $28^{\circ}$ for 3 days. Five hundred colonies were then retested for growth at $43.5^{\circ}$ and for hypersensitivity to $5 \mathrm{~mm}$ HU. Candidates for further study were subjected to genetic crosses to determine if the suppression was due to a mutation in a single gene and if the HU hypersensitivity and the suppression cosegregated.

Staining, microscopy, and measurements: Growth of strains on coverslips, fixation of samples, staining with Calcofluor White and Hoechst 33258, and mounting of coverslips on glass slides were performed as previously described (HARRIs et al. 1994). Microscopy, photography, and measurements were performed as previously described (Harris and Kraus 1998). Cell size was determined by measuring hyphal length using a calibrated eyepiece micrometer. Since fungal hyphae grow solely at the tip, the length of a hypha generally indicates the extent to which it has grown. Under the conditions used in these experiments, the average hyphal diameters of all strains were similar although slight variations were observed. The nonparametric Mann-Whitney test was used to determine if two strains differed significantly in cell length and cell width (ZAR 1984). To use this test, measurements were ranked and the $U$ and $U^{\prime}$ values calculated. These values take the number of measurements and the sum of the ranks into consideration. The larger of the two values was compared to the respective critical value. If the $U$ or $U^{\prime}$ value was greater than or equal to the respective critical value, the null hypothesis (that no significant difference in cell length or cell width exists) was rejected. The septation index (SI) represents the percentage of germlings that contain at least one septum $(n \geq 200)$. The chromosome mitotic index (CMI) represents the percentage of cells that contain condensed mitotic chromatin $(n=200)$.

Protein extraction and Y15-phosphorylation assays: Strains were inoculated in YGV at $5 \times 10^{6}-1 \times 10^{7} \mathrm{conidia} / \mathrm{ml}$ at $28^{\circ}$. Mycelia were harvested by filtration, rinsed in stop buffer (MoRENO et al. 1989), pressed dry between paper towels, and frozen in liquid nitrogen. We extracted protein from frozen mycelia in HK buffer (Osmani et al. 1991) using a ground glass dounce homogenizer at $4^{\circ}$. Samples were centrifuged for $10 \mathrm{~min}$ at $14,000 \times \mathrm{g}$ and the supernatant was removed. We used $2 \mathrm{mg}$ of protein for affinity purification of NIMX ${ }^{\mathrm{cdk} 1}$ using $\mathrm{p} 13^{\text {suc } 1}$ agarose beads (Oncogene Research Products). For Western blots, proteins were separated by SDS-PAGE and transferred to Immobilon-P membranes (Millipore, Bedford, MA) by electroblotting with a semidry apparatus (Hoefer Scientific Instruments, San Francisco). Western analysis was performed by enhanced chemiluminescence (ECL; Amersham Life Sciences, Buckinghamshire, UK) according to the manufacturer's specifications. Membranes were probed with Y15 phospho-specific anti-Cdc2 antibodies (New England Biolabs, Beverly, MA) and antiPSTAIRE antibodies (Santa Cruz Biotechnology) as a loading control and were used at dilutions of 1:1000 and 1:2000, respectively.

Cloning and identification of sntA: To clone the sntA gene, we used a genomic plasmid library that contains a sequence (AMA1) that allows autonomous replication in A. nidulans (OsHEROV and MAY 2000). Use of this autonomously replicating plasmid greatly increases transformation efficiency and facilitates recovery of the plasmid from transformants for subsequent cloning steps. Transformants were recovered on $5 \mathrm{~mm}$ HU and streak purified twice in the presence of HU. Genomic DNA was prepared from transformants and used to transform electrocompetent Escherichia coli cells, and 24 ampicillin-resistant colonies were analyzed for the recovery of the vector containing a genomic insert. Plasmids that contained a genomic insert were confirmed by the ability to retransform to HU resistance. Fragments of genomic inserts were subcloned into the plasmid pBluescript (Stratagene, La Jolla, CA) and sequenced at the Molecular Core Facility at the University of Connecticut Health Center. Partial sequence of a 3-kb $X b a I$ genomic fragment was identical to the previously described ankA gene (accession no. U25693). In addition, a sequence was obtained that is likely to encode the small subunit of the $A$. nidulans ribonucleotide reductase and was designated $m r A$ (accession no. AF310625; see below). 


\section{TABLE 1}

Aspergillus nidulans strains

\begin{tabular}{|c|c|c|}
\hline Strain & Genotype & Source $^{a}$ \\
\hline ASH35 & $\operatorname{sepA1;} \operatorname{argB2} ; y A 2$ & Lab stock \\
\hline ASH60 & sepB3; pabaA6; yA2 & Lab stock \\
\hline ASH202 & sepB3; uvsB110; pabaA1; nicA2 & Lab stock \\
\hline ASH244 & $\operatorname{nim} X 3 ; \arg B 2 ; w A 3$ & Lab stock \\
\hline ASH278 & $\operatorname{nim} T 23 ; \arg B 2 ; w A 3$ & Lab stock \\
\hline ASH288 & $\operatorname{sepB3;}$ nimX $X^{\text {cdc2AF}} ;$ pabaA6 & Lab stock \\
\hline AAH1 & nimA5; uvsB110; wA3 & Lab stock \\
\hline A28 & pabaA6; biA1 & 1 \\
\hline A781 & $\operatorname{nimA5} ; w A 3$ & 1 \\
\hline FRY20 & nim $X^{\text {cdc2AF }} ; w A 3 ;$ pyrG89; pyroA4; pyr4 $4^{+}$ & 2 \\
\hline GR5 & pyrG89; pyroA4; wA3 & 1 \\
\hline MO73 & nimT23; pabaA6 & 2 \\
\hline SO65 & nimX3; pyroA4; riboA1; wA3; yA2 & 2 \\
\hline APK35 & sntA1; pabaA6 & This study \\
\hline APK47 & sepB3; sntC1 & This study \\
\hline APK53 & sepB3; sntB1; pabaA6; yA2 & This study \\
\hline APK56 & sntB1; pabaA6 & This study \\
\hline APK61 & sepB3; sntA $1 ;$ pabaA6 & This study \\
\hline APK64 & sntC1; pabaA6 & This study \\
\hline APK66 & nimX3; sntB1; wA3 & This study \\
\hline APK68 & nimX3; sntA1; wA3 & This study \\
\hline APK69 & sepA3; sntA1; $\arg B 2 ; y A 2$ & This study \\
\hline APK70 & $\operatorname{sepA3;}$ sntB1; $\arg B 2$ & This study \\
\hline APK72 & nimA5; sntA1; pabaA6; wA3 & This study \\
\hline APK73 & nimA5; sntB1; pabaA6; wA3 & This study \\
\hline APK107 & sntA1; pyrG89; chaA1; [pAMA1-ankA] & This study \\
\hline APK110 & $\operatorname{snt} A 1 /+; \operatorname{sntB} 1 /+$ & This study \\
\hline APK111 & $\operatorname{sntA} 1 /+; \operatorname{snt} B 1 /+$ & This study \\
\hline
\end{tabular}

${ }^{a}$ Key to sources: 1, Fungal Genetics Stock Center, Department of Microbiology, University of Kansas Medical Center, Kansas City, KS 66160-7420; 2, Stephen Osmani, Weis Center for Research, Pennsylvania State University College of Medicine, Danville, PA 17822.

\section{RESULTS}

Isolation of $\mathrm{Ts}^{+}$suppressors of the heat-sensitive nimT23 mutation: Suppressors of the heat sensitivity caused by the nimT23 mutation were isolated as described in MATERIALS AND METHODS. Conidia from the strain MO73 were plated on CM plates and irradiated with UV light. Five hundred revertants were then retested for growth at $43.5^{\circ}$ and for hypersensitivity to $5 \mathrm{~mm} \mathrm{HU}$. The rationale was to facilitate future cloning of the suppressor genes by complementation of the HU hypersensitivity. We chose HU hypersensitivity as a selectable phenotype because mutants that are able to bypass the $\mathrm{G}_{2}$ cell cycle arrest of the nimT23 mutant might also be defective in cell cycle checkpoint function.

Of the 500 snt mutants (suppressor of nimT23) isolated by the ability to grow at $43.5^{\circ}, 90$ did not form a colony on $\mathrm{CM}+5 \mathrm{~mm}$ HU plates. These were then crossed with the nimT23 strain ASH278 to determine if the HU hypersensitivity cosegregated with suppression of the Ts phenotype. For 20 of the 90 mutants, suppression was linked to the HU hypersensitivity because all $\mathrm{Ts}^{+}$segre- gants were $\mathrm{HU}^{\mathrm{s}}$. Fifteen extragenic suppressors were then isolated by the appearance of Ts segregants after crossing each mutant with the wild-type strain GR5. One class of mutants we expected to isolate from this screen was loss-of-function alleles of $a n k A$, the gene encoding the A. nidulans ortholog of Weelp, which is responsible for the inhibitory Tyr-15 phosphorylation of NIMX ${ }^{\text {cdk1 }}$. The ankA gene is tightly linked to the $w A$ locus (X. YE, personal communication); therefore, any suppressors that were linked to the $w A$ locus after the cross with ASH278 were likely to contain a mutation in the ankA gene. Although one extragenic suppressor (A86, sntA linkage group) appeared to display loose linkage to $w A(6 / 36$ recombinants), we continued with its characterization. In addition, the suppressors were also crossed with the strain ASH244 to verify that they did not have a mutation in the nim $X$ gene.

The 15 extragenic suppressors were examined microscopically to determine if septum formation was occurring prematurely. For these experiments, the SI was determined and compared to that of a wild-type strain. Since A. nidulans hyphae grow solely at the tip and the hyphal diameter of all strains was constant, cell size could be determined by measuring hyphal length. Seven snt mutants were chosen for subsequent linkage analysis on the basis that they showed a significant decrease in cell size at the time of septation compared to the wildtype control (see below), whereas the other eight mutants showed no such difference. These mutants sorted into three linkage groups, designated $s n t A$, sntB, and $s n t C$. These snt mutations are recessive because heterozygous diploids are able to form a colony on $5 \mathrm{~mm} \mathrm{HU}$ (P. R. Kraus and S. D. Harris, unpublished results). $s n t A$ and $s n t B$ define distinct complementation groups because diploids constructed from $s n t A$ and $s n t B$ parent strains were able to form a colony on plates containing 5 mм HU (Figure 1). No diploids were able to be constructed between $s n t C$ and $s n t A$ or $s n t B$ mutants. The $s n t A$ and $s n t C$ linkage groups contain only one isolate each, designated sntA1 and sntC1, respectively. The other five suppressors comprise the $s n t B$ linkage group. The D80 isolate, designated $s n t B 1$, was chosen for further study because its $\mathrm{HU}^{\mathrm{s}}$ phenotype was strongest. Due to the inability to assign $s n t C$ to a complementation group, only preliminary phenotypic characterization was performed. The viability curves for sntA1, sntB1, and sntC1 mutants plated on media containing HU are shown in Figure 1.

sntA1, sntB1, and sntC1 mutations cause deregulation of septum formation: In wild-type $A$. nidulans germlings, septum formation does not occur until the hyphae have grown longer than 45-50 $\mu \mathrm{m}$ and have completed three or four rounds of nuclear division (HARRIs et al. 1994; Wolkow et al. 1996). It has previously been shown that NIMX ${ }^{\text {cdk1 }}$ activity is required for septum formation and that septum formation occurs inappropriately when NIMX $^{\text {cdk1 } 1}$ is deregulated (HARris and Kraus 1998). Since 
$\mathbf{A}$

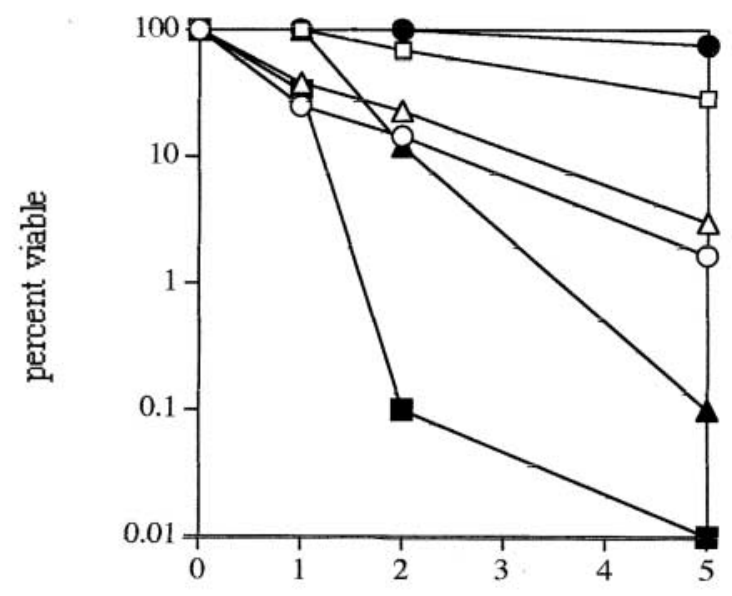

$[\mathrm{HU}]$ in $\mathrm{mM}$

\section{B}

MNV

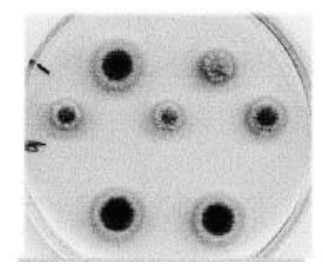

MNV + 5 mM HU

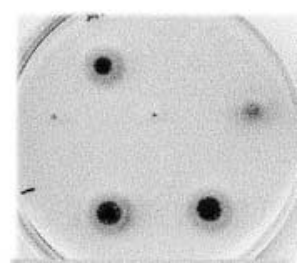

Figure 1.-sntA1, sntB1, and sntC1 mutants are hypersensitive to HU. (A) Conidia from strains A28 (wild type, solid circles), APK35 (sntA1, open circles), APK56 (sntB1, open triangles), APK64 (sntC1, open squares), ASH201 (uvsB110, solid triangles), and FRY20 ( $\operatorname{mim} X^{\text {cd } 2 A F}$, solid squares) were diluted and plated at 100 conidia per plate on CM media containing the indicated concentration of HU. The number of survivors on each plate was determined after 3 days incubation at $32^{\circ}$. Percent viability represents the percentage of colonies remaining on the treated plates as compared to the untreated control plates. Each data point represents the average of four plates. Experiments were repeated twice, and representative data are shown. (B) Conidia from the indicated strains were point inoculated on $\mathrm{MNV}$ and $\mathrm{MNV}+5 \mathrm{~mm} \mathrm{HU}$ and incubated for 3 days at $32^{\circ}$. (Top row) A28 (wild type) and FRY20 (nimX $\left.X^{\text {cd } 2 A F}\right)$; (middle row) APK35 (sntA1), APK56 (sntB1), and APK64 (sntC1); (bottom row) APK110 (sntA1/+; $s n t B 1 /+$ diploid) and APK111 (sntA1/+; sntB1/+ diploid).

the NIMT tyrosine phosphatase is required for the activation of NIMX ${ }^{\text {cdk1 }}$, loss-of-function mutations in genes whose products negatively regulate NIMT might result in premature activation or elevated levels of NIMX $\mathrm{Xdk}^{\mathrm{ck}}$ activity. Accordingly, a subset of the snt mutants may display a premature septum formation phenotype. As predicted, cells harboring the sntA1, sntB1, and sntC1 mutations underwent septum formation at a smaller size and with fewer nuclei than did wild-type cells (Figure $2)$. The mean length of wild-type cells possessing one septum $(61.7 \pm 15.2 \mu \mathrm{m})$ differs significantly from that of the sntA1 mutant $(24.5 \pm 7.3 \mu \mathrm{m} ; Z=0.001, Z=$
5.87), the sntB1 mutant $(24.4 \pm 6.7 \mu \mathrm{m} ; \alpha=0.001, Z=$ $5.93)$, and the sntC1 mutant $(25.6 \pm 7.8 \mu \mathrm{m} ; \alpha=0.001$, $Z=5.89$ ) on the basis of the nonparametric MannWhitney test. Furthermore, 10-15\% of sntA1, sntB1, and sntC1 cells underwent septation at a size smaller than $25 \mu \mathrm{m}$, whereas no wild-type cells formed septa at this size. In addition, between 16 and $26 \%$ of sntA1, sntB1, and sntC1 cells contained four or fewer nuclei when the first septum formed (Figure 3), a condition that is never observed in wild-type cells (HARris et al. 1994). A significant percentage of $s n t A 1$, sntB1, and sntC1 cells also contained nuclei that were bisected by a septum (5$16 \%$ ) or contained a double septum (2-5\%; Figure 3$)$, which is similar to the effect caused by the nim $X^{\text {dd } 2 A F}$ mutant (HARris and Kraus 1998).

Previous results have shown that general perturbations of DNA metabolism in A. nidulans germlings inhibit or delay the formation of the first septum (HARRIS and Kraus 1998). The Ts sepB3 mutation causes defects in normal chromosomal DNA metabolism at the nonpermissive temperature, and the formation of the first septum is blocked (HARris and HAMER 1995). In sepB3 mutants that are defective in cell cycle checkpoint functions due to the presence of either the $u v s B 110$ or the $n i m X^{d d 2 A F}$ mutations, the inhibition of septum formation is relieved and the SI approaches wild-type levels (HARRIS and Kraus 1998). To test whether the sntA1, sntB1, and sntC1 mutations cause a similar effect, sepB3 snt double mutants were constructed and tested for the ability to undergo septum formation at the restrictive temperature. sepB3 snt double mutants were found to be Ts for growth and hypersensitive to $5 \mathrm{~mm} \mathrm{HU}$ at the permissive temperature. Despite the presence of the sepB3 mutation, the sepB3 snt double mutants were all able to form septa at the restrictive temperature of $42^{\circ}$ (Table 2). The septation index in sepB3 sntA1 mutants was $40.0 \pm 7.5$, while the septation indices in $\operatorname{sep} B 3$ sntB1 and sepB3 sntC1 mutants were $\sim 70$, which is similar to that of the sepB3 nim $X^{\text {dd } 2 A F}$ mutant (see DISCUSSION). In addition, cells possessing the sntA1, sntB1, and sntC1 mutations were able to undergo septum formation when grown in the presence of $0.025 \% \mathrm{DEO}$, a bifunctional alkylating agent (P. R. Kraus and S. D. HARris, unpublished results). The possibility that the $\operatorname{sntA1}$, sntB1, and sntC1 mutations can bypass the normal controls that regulate septum formation was eliminated by showing that sepA3 snt double mutants do not undergo septum formation at restrictive temperature. The product of the sepA gene is thought to be required for organization of the actin ring at the division site (HARRIS et al. 1997). These results show that the regulatory mechanisms that restrain septum formation when hyphal cells are either too small or have sustained DNA damage are abrogated by the sntA1, sntB1, and sntC1 mutations.

The DNA damage checkpoint pathway is compromised in sntA1 and sntB1 mutants: The results reported above show that sntA 1 and sntB1 mutants do not delay septum 
A wild type (SI=38.0)

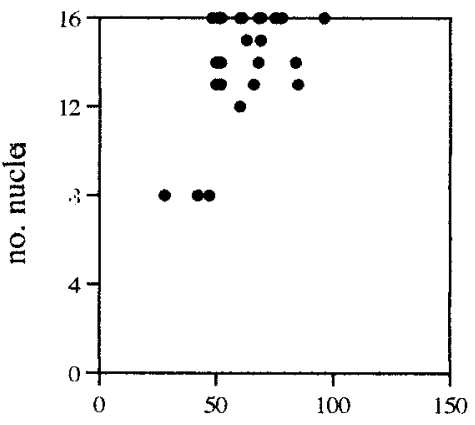

hyphal length $(\mu \mathrm{m})$

C $\operatorname{sntBl}(\mathbf{S I}=36.0)$

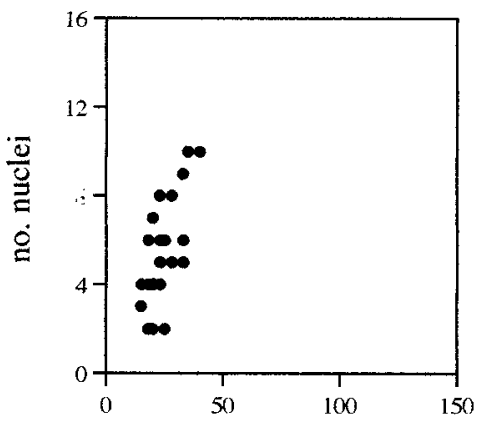

hyphal length $(\mu \mathrm{m})$
B $\operatorname{sntAl}(\mathrm{SI}=48.0)$

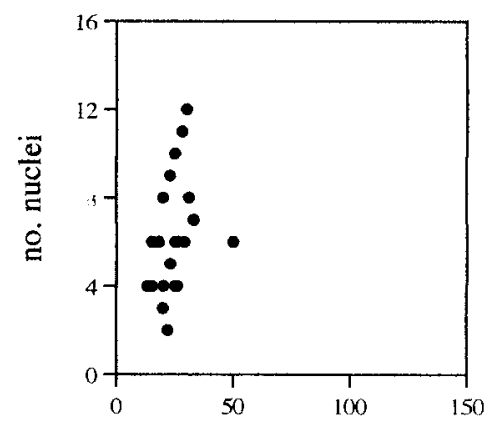

hyphal length $(\mu \mathrm{m})$

D $s n t C l(S I=40.0)$

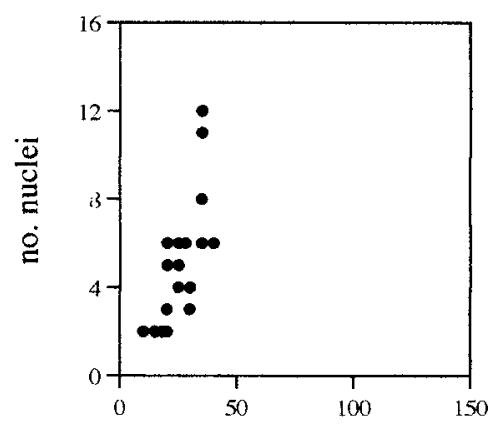

hyphal length $(\mu \mathrm{m})$
FIGURE 2.- $-s n t A 1$, sntB1, and sntC1 mutants undergo septum formation at a smaller size and with fewer nuclei than do wild-type cells. Conidia of the indicated genotypes were incubated on coverslips for $11 \mathrm{hr}$ (wild type) or 12 hr (snt mutants) at $28^{\circ}$, such that the septation indices of the populations were similar. Coverslips were stained with Calcofluor White and Hoechst 33258 to visualize septa and nuclei, respectively. For each strain, the length and nuclear number of 25 cells possessing one septum were measured and plotted as a scatter graph. In addition, the SI was determined for a randomly selected population of 200 cells. The strains analyzed were the following: (A) A28, (B) APK35, (C) APK56, and (D) APK64. formation in response to DNA damage as do wild-type cells. To test whether the DNA damage checkpoint pathway is nonfunctional in sntA1 and sntB1 mutants, we tested their ability to inhibit nuclear division in the presence of DNA damage. The sntA1 and sntB1 mutations were crossed into a background containing the Ts nimA5 mutation, which causes a $\mathrm{G}_{2}$ arrest at restrictive temperature (Osmani et al. 1987). The nimA5 snt double
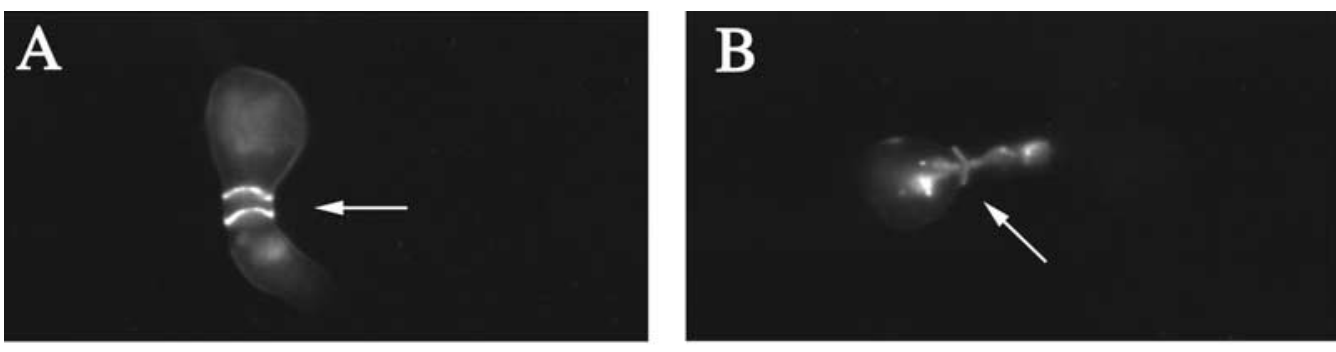

FiguRe 3.-Septum formation is deregulated in sntA1, sntB1, and sntC1 mutants. Conidia were germinated on coverslips for 11-12 hr at $28^{\circ}$. Coverslips were stained with Calcofluor White and Hoechst 33258 to visualize septa and nuclei, respectively. (A) APK35 (sntA1) shows a cell with a double
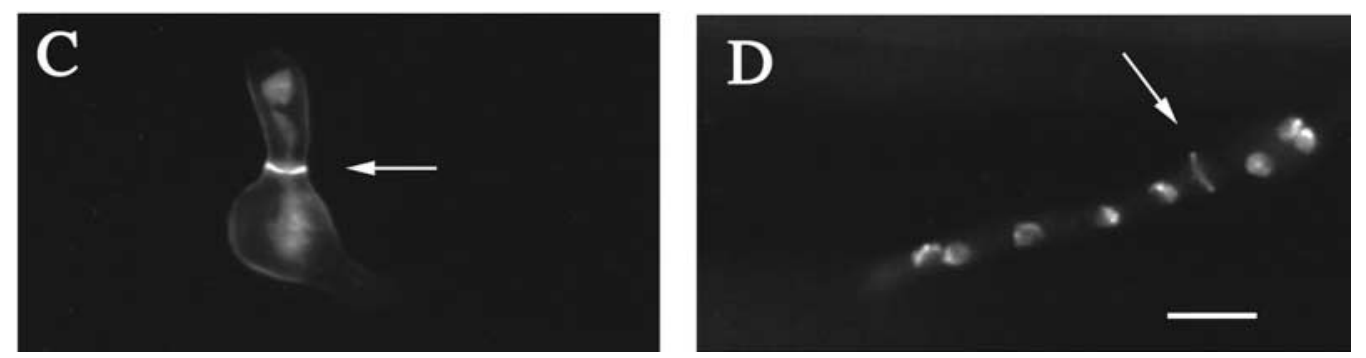
septum. (B) APK56 (sntB1) and (C) APK64 (sntC1) show cells in which the nuclear material is bisected by a septum ("cut" phenotype). (D) A28 (wild type). Septa are denoted by arrows. Hyphal widening occurred in snt mutant strains at a low frequency; however, the average hyphal diameters of snt strains were not significantly different from the diameter of wild-type strains as determined by the Mann-Whitney test $(\alpha=$ 0.001; see MATERIALS AND METHODS). Bar, $10 \mu \mathrm{m}$. 
TABLE 2

Septation indices of $\operatorname{sepB} 3$ snt double mutants

\begin{tabular}{llr}
\hline Strain & \multicolumn{1}{c}{ Genotype } & Septation index \\
\hline A28 & Wild type & $84.2 \pm 2.2$ \\
ASH60 & sepB3 & $1.7 \pm 1.2$ \\
ASH288 & sepB3 nim Cdc2AF $^{\text {APK61 }}$ & $69.8 \pm 2.8$ \\
APK53 & sepB3 sntA1 & $40.0 \pm 4.4$ \\
APK47 & sepB3 sntC1 & $69.5 \pm 1.0$ \\
APK66 & nimX3 sntA1 & $68.2 \pm 1.9$ \\
APK67 & nimX3 sntB1 & 0 \\
APK69 & sepA1 sntA1 & 0 \\
APK70 & sepA1 sntB1 & 0 \\
\hline
\end{tabular}

Conidia from the indicated strains were germinated on coverslips for $12-16 \mathrm{hr}$ at $42^{\circ}$. Coverslips were stained with Calcofluor White and Hoechst 33258 to visualize septa and nuclei, respectively. For each strain, 200 germlings were scored for the presence of septa. The SI represents the percentage of cells that contain one or more septa. Experiments were repeated three times; data shown are the mean SI and the standard error of the mean.

mutants were incubated at the restrictive temperature of $43.5^{\circ}$ for $8 \mathrm{hr}$ and then shifted to permissive temperature in either YGV or YGV containing $0.025 \%$ DEO. Cells harboring the nimA5 mutation displayed a significant increase in the CMI after release into the control media, whereas the CMI remained low when they were released into media containing DEO (Figure 4A). In contrast, nimA5 sntA1 and nimA5 sntB1 cells showed a significant increase in the CMI when released into media containing DEO (Figure 4, B and C). The failure to delay nuclear division in the presence of DNA damage in the nimA5 snt double mutants is very similar to the behavior of the nimA5 uvsB110 mutant (Figure 4D), which no longer has a functional DNA damage checkpoint (HOFMANN and HARRIS 2000). These results show that the checkpoint that prevents mitotic entry due to the presence of DNA damage is compromised in sntA1 and sntB1 mutants.

The $s n t A 1$ and $s n t B 1$ mutations have different effects on cell cycle progression in the presence of the sepB3 mutation: Conidia that harbor the $\operatorname{sepB} 3$ mutation display a progressive cell cycle delay when incubated at restrictive temperature (HARRIS and HAMER 1995). This delay may allow repair of DNA damage that is caused by the lack of a functional $s e p B$ gene. The delay is presumably caused by the DNA damage or replication checkpoint, since it is abolished by the nim $X^{\text {dd } 2 A F}$ and uvsB110 mutations (Hofmann and Harris 2000). To ask if the $s n t A 1$ and sntB1 mutations similarly abolished the cell cycle delay imposed by the loss of $\operatorname{sep} B$ function, we examined the nuclear division kinetics of $s e p B 3$ snt double mutants. We found that the snt mutations had different effects on the cell cycle delay caused by the presence of the $\operatorname{sep} B 3$ mutation (Figure 5). The $\operatorname{sepB3}$ sntA1 double mutant resembled $\operatorname{sepB} 3$ nim $X^{\text {dd } 2 A F}$ and
sepB3 uvsB110 cells in that the cell cycle delay was abrogated (i.e., hyphal cells accumulated four nuclei with kinetics similar to wild type). In contrast, the $\operatorname{sepB} 3$ sntB1 double mutant showed a cell cycle delay similar to that of sepB 3 cells. These results show that the sntB1 mutant is distinct from the sntA1 mutant in that it is not dysfunctional in all checkpoints involving $u v s B$ or Tyr-15 phosphorylation of NIMX ${ }^{\text {cdk1 }}$.

Reduced Tyr-15 phosphorylation in sntA1 and sntB1 mutants: Activation of the $\mathrm{G}_{2} / \mathrm{M}$ DNA damage checkpoint in A. nidulans requires phosphorylation of Tyr-15 of NIMX ${ }^{\text {cdk1 }}$ (YE et al. 1997). One reason that the sntA1 and sntB1 mutants might be defective in the DNA damage checkpoint is that the removal of the phosphate group at position 15 by the NIMT phosphatase may not be prevented when the checkpoint is activated. Alternatively, the sntA1 and sntB1 mutants may not be able to undergo the inhibitory phosphorylation event even under normal conditions. To test this, we assessed the phosphorylation state of NIMX ${ }^{\text {cdk1 } 1}$ in wild-type and sntA1 and sntB1 mutant cells by affinity purifying NIMX ${ }^{\text {cdk1 }}$ from exponentially growing cells incubated in YGV or in YGV $+0.025 \%$ DEO. The phosphorylation state of NIMX $^{\text {cdk1 } 1}$ was assayed by Western blot using phosphospecific anti-Cdc2 antibodies. Exponentially growing sntA1 and sntB1 cells that have not been treated with DEO show greatly reduced phosphorylation when compared with wild-type cells (Figure 6). In addition, no induction of Tyr-15-phosphorylated NIMX ${ }^{\text {cdk1 }}$ occurs after growth in the presence of DEO for $1 \mathrm{hr}$. Although the effects of adding DEO to wild-type cultures are presumably obscured by the asynchrony of the culture, these results are consistent with the notion that the sntA1 and sntB1 mutants either fail to undergo Tyr-15 phosphorylation or fail to prevent Tyr-15 dephosphorylation.

sntA encodes the cell cycle regulator ANKA: $s n t A$ was cloned by complementation of the HU hypersensitivity using an autonomously replicating AMA1-based genomic library (Osherov and MAY 2000). Transformation of the snt mutants using this library yielded two types of plasmids. One type of plasmid contained the A. nidulans gene encoding the small subunit of ribonucleotide reductase, which we named $m r A$ (accession no. AF310625). The small subunit of ribonucleotide reductase is the target of HU (Desany et al. 1998), which suggests that multiple copies of the $m r A$ gene complement only the HU sensitivity of the sntA1 and sntB1 mutants. Consistent with this notion, $r m r A$ introduced in single copy did not complement the HU hypersensitivity of either sntA1 or sntB1, and sntA 1 and sntB1 mutants containing the multicopy $m r A$ plasmid still formed septa inappropriately (P. R. Kraus and S. D. Harris, unpublished results). The other type of plasmid contained sequences identical to the previously identified ankA gene (Ye et al. 1996). ankA encodes a tyrosine kinase that is responsible for catalyzing the inhibitory phosphorylation of NIMX ${ }^{\text {cdk1 }}$ on tyrosine 15 . In A. nidu- 
A $\operatorname{nimA5}$

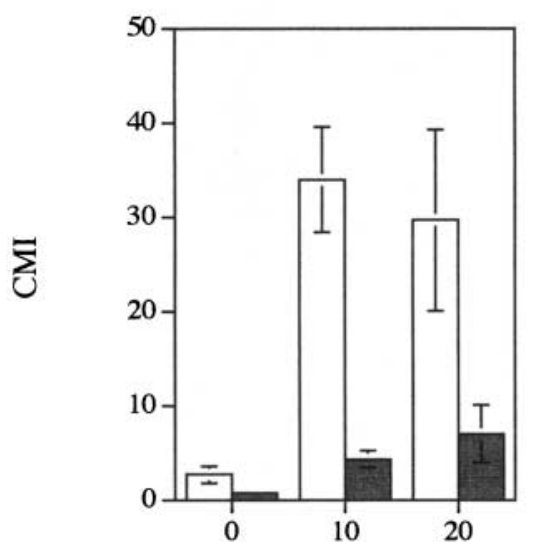

time after release from $43.5^{\circ}(\mathrm{min})$

C nimA5; sntB1

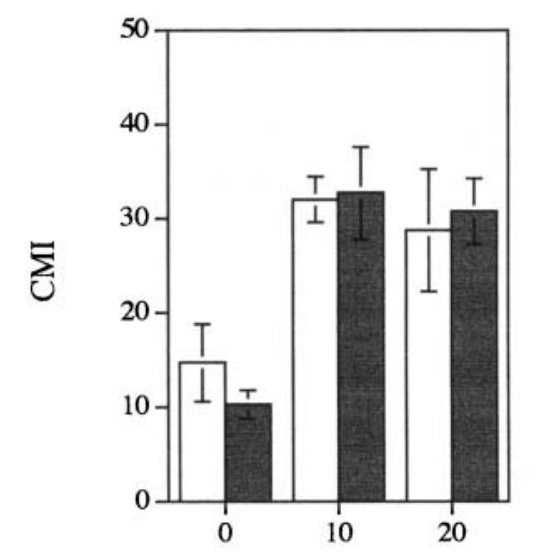

time after release from $43.5^{\circ}(\mathrm{min})$
B nimA5; sntA1

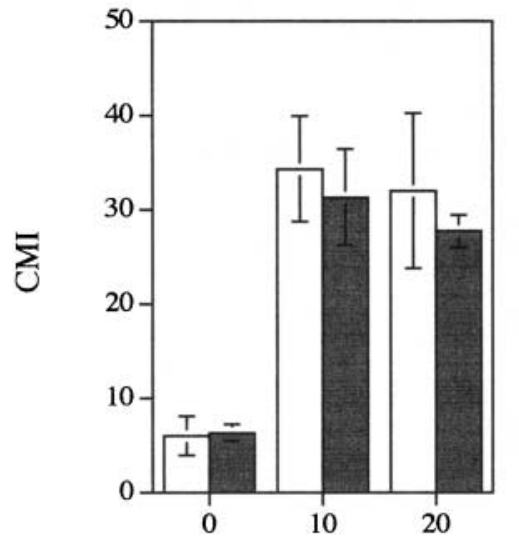

time after release from $43.5^{\circ}(\mathrm{min})$

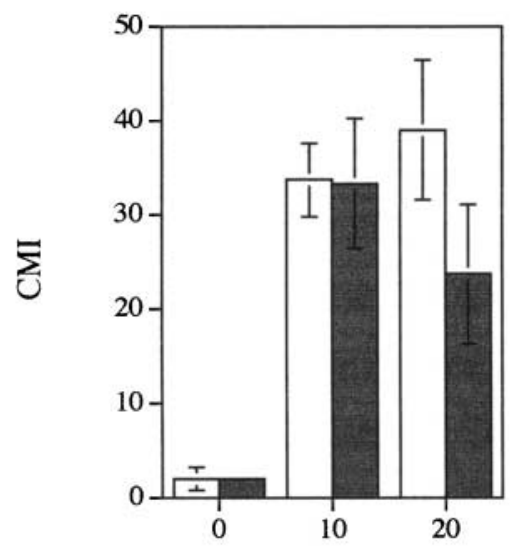

time after release from $43.5^{\circ}(\mathrm{min})$
FIGURE 4.-The DNA damage checkpoint is abrogated in sntA 1 and sntB1 mutants. Conidia from strains with the indicated genotype were germinated in YGV at $43.5^{\circ}$ for $8 \mathrm{hr}$ and released at $28^{\circ}$ into YGV (open bars) or YGV + $0.025 \%$ DEO (solid bars). Samples were taken at the indicated time points and the CMI was determined for each sample by counting 200 cells and determining the percentage that contain condensed mitotic chromatin $(n=3)$. Data shown are the mean CMI and the standard error of the mean. Strains used were (A) A781, (B) APK72, (C) APK73, and (D) AAH1. lans, the $\triangle a n k A$ mutant has been shown to be defective in the slowing of S-phase checkpoint (YE et al. 1996), the DNA damage checkpoint (YE et al. 1997), and the regulation of septum formation (DE SouzA et al. 1999). The sntB1 mutant is also complemented, but to a slightly lesser extent, by the ankA gene when it is present on the AMA1-based plasmid. The loose linkage of $s n t A$ to $w A$ suggests that $s n t A$ is an allele of $a n k A$, whereas $s n t B$ is likely to be rescued by the introduction of multiple copies of ankA. To test this notion, sntA1 and sntB1 strains were transformed with an integrating plasmid containing ankA. A 3.8-kb EcoRI fragment containing ankA was subcloned into pRG3, which contains the Neurospora crassa pyr-4 gene (WARING et al. 1989). $\mathrm{Pyr}^{+}$transformants were tested for the ability to grow in the presence of $5 \mathrm{~mm} \mathrm{HU}$. To screen for gene replacement events in these transformants, these strains were cured of the plasmid by growth on nonselective media containing 5-FOA. The resulting 5-FOA-resistant strains were tested for the ability to grow in the presence of 5 mu HU. A total of $59 \%(n=124)$ of the 5-FOA-resistant strains derived from the sntA 1 strain were able to grow in the presence of $5 \mathrm{~mm} \mathrm{HU}$, indicating that the sntAl lesion is repaired by loss of the ankA-containing plasmid. No such HU-resistant colonies were found with 5-FOAresistant strains derived from $\operatorname{sntB1}$ transformants $(n=$ 100). We conclude that $s n t A 1$ is an allele of $a n k A$, while the sntB1 mutation is in a different gene and can be complemented by ankA in multiple copies. Repeated attempts to clone $s n t B$ failed to identify a plasmid specific to sntB1 complementation.

Growth conditions affect the regulation of septum formation and the sntA1 and sntB1 phenotypes: Previous experiments that characterized the regulation of sep- 


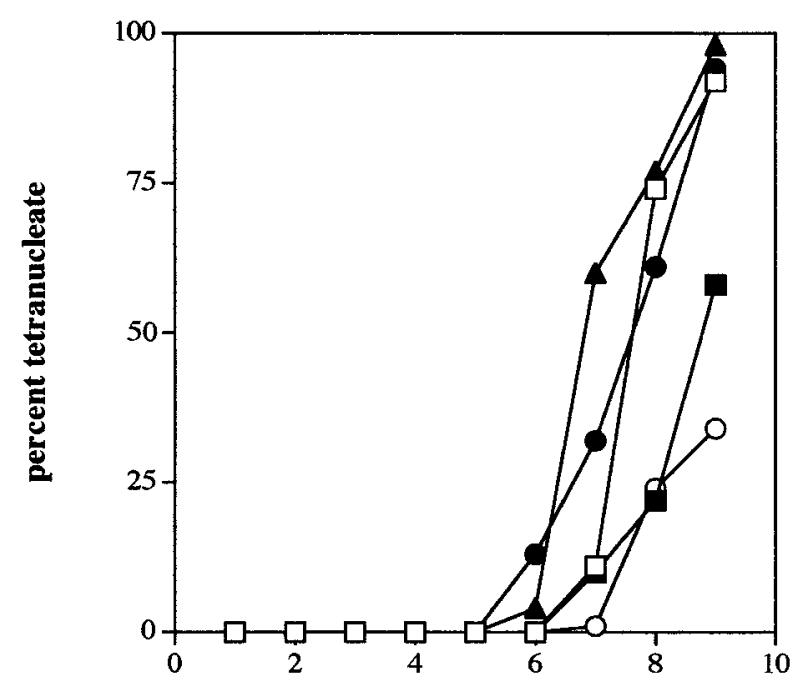

hours at $42^{\circ}$

Figure 5.-sntA1 and sntB1 mutants have different effects on cell cycle progression in the sepB3 background. Conidia from strains A28 (wild type, open squares), ASH60 (sepB3, solid squares), ASH202 (sepB3 uvsB110, solid triangles), APK53 (sepB3 sntB1, open circles), and APK61 (sepB3 sntA1, solid circles) were germinated on coverslips for $4 \mathrm{hr}$ at $42^{\circ}$. Thereafter, one coverslip was removed every hour over a 5 -hr period and processed for microscopy. Coverslips were stained with Calcofluor White and Hoechst 33258 to visualize septa and nuclei, respectively. For each sample, 200 germlings were scored for the number of nuclei present. Data points represent the percentage of germlings possessing four or more nuclei. The experiment was repeated three times, and representative data are shown.

tum formation in A. nidulans were performed in rich media (Harris et al. 1994; Wolkow et al. 1996). To assess the role of growth conditions and/or nutrient availability in the regulation of septum formation, we performed a series of experiments using minimal media containing different carbon sources. Conidia from wildtype and snt mutants were incubated on coverslips in YGV for $8 \mathrm{hr}$ and shifted to MNV-glycerol, and the timing of septum formation was determined relative to nuclear division and cell length. Wild-type cells that have been shifted to MNV-glycerol underwent septum formation at a significantly smaller size and with fewer nuclei than did the cells that remained in YGV for the duration of the experiment (Table 3). However, sntA1 and sntB1 mutants underwent septation at a small size irrespective of whether they were shifted to MNV-glycerol or remained in YGV. These data suggest that nutrient availability influences the timing of septum formation and that the $s n t A$ and $s n t B$ genes are required to delay septum formation under rich media conditions.

To further assess the effect of nutritional conditions on the sntA 1 and sntB1 phenotype, the effects of altering the carbon source on the HU hypersensitivity of the sntA 1 and sntB1 mutants were investigated. The viability of the sntA1 and sntB1 mutants following incubation on

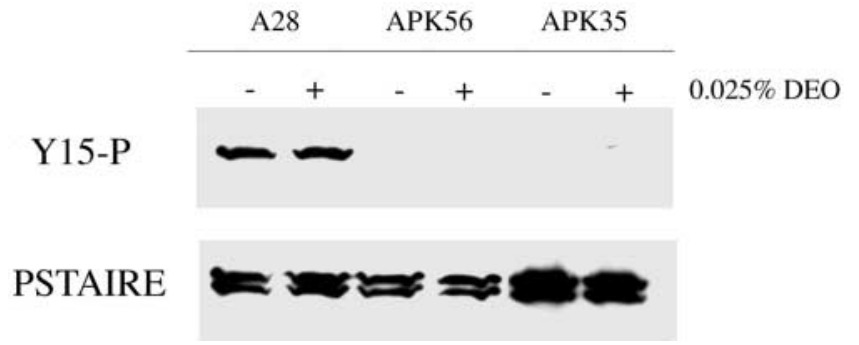

Figure 6.- Reduced Tyr-15 phosphorylation in sntA1 and sntB1 mutants. Conidia from strains A28 (wild type), APK 56 (sntB1), and APK35 (sntA1) were inoculated in YGV and grown for $12 \mathrm{hr}$ at $28^{\circ}$. One-half of the cultures were harvested for protein extraction and the remaining one-half was treated with $0.025 \%$ DEO for $1 \mathrm{hr}$ before harvesting. Protein was extracted and NIMX ${ }^{\text {cdk1 }}$ was affinity purified using $\mathrm{p} 13^{\text {sucl } 1}$ agarose beads. Proteins were separated by SDS-PAGE and transferred to Immobilon-P by electroblotting with a semidry apparatus. Western analysis was performed by ECL according to the manufacturer's specifications. Membranes were probed with Y15 phospho-specific anti-Cdc2 antibodies at 1:1000, stripped, and reprobed with anti-PSTAIRE antibodies at 1:2000.

MNV, MNV-OAc, and MNV-EtOH media in the presence of varying concentrations of $\mathrm{HU}$ was determined. When incubated on MNV, sntA1 and sntB1 mutants displayed a significant loss of viability in the presence of HU compared to the wild type (Figure 7). However, the viability of the sntA1 and sntB1 mutants was substantially improved at even the highest concentrations of $\mathrm{HU}$ when incubated on MNV-OAc or MNV-EtOH (Figure 7). In particular, sntA1 mutants were almost fully viable in the presence of $\mathrm{HU}$ when incubated on MNV-OAc. These observations suggest that the sntA and $s n t B$ gene products are partially dispensable for the checkpoint that responds to low concentrations of $\mathrm{HU}$ when hyphal cells are incubated on media containing acetate or ethanol as the sole carbon source. This effect appears to be specific to the carbon source, since amino acid starvation induced by $3 \mathrm{AT}(0.5 \mathrm{~mm})$ did not increase the viability of the sntA 1 and sntB1 mutants in the presence of HU (P. R. Kraus and S. D. Harris, unpublished results).

While demonstrating that the ankA gene could complement all phenotypes caused by the sntA 1 mutation, we were surprised to observe that sntA1 mutants containing the AMA1-ankA plasmid were extremely hypersensitive to HU when incubated on MNV-EtOH (compare solid squares in Figure 7, B and D). In contrast, these transformants displayed similar viability to wildtype cells when incubated on MNV (Figure 7D). These results are consistent with a model that suggests that ANKA levels are reduced under conditions where nutrients are scarce (see below).

\section{DISCUSSION}

Previous studies have shown that germinating $A$. nidulans conidiospores are not competent to undergo septa- 


\section{TABLE 3}

Growth conditions affect the timing of septum formation

\begin{tabular}{llcc}
\hline Strain & & MNV-glycerol & YGV \\
\hline A28 & Length $(\mu \mathrm{m})$ & $29.5 \pm 8.5$ & $60.5 \pm 16.9$ \\
& No. nuclei (mode) & 8 & 16 \\
APK35 & Length $(\mu \mathrm{m})$ & $24.8 \pm 10.3$ & $25.0 \pm 9.8$ \\
& No. nuclei (mode) & 8 & 4 \\
\multirow{2}{*}{ APK56 } & Length $(\mu \mathrm{m})$ & $23.5 \pm 8.3$ & $22.4 \pm 7.3$ \\
& No. nuclei (mode) & 8 & 8 \\
FRY20 & Length $(\mu \mathrm{m})$ & $26.5 \pm 10.3$ & $24.1 \pm 8.4$ \\
& No. nuclei (mode) & 8 & 8 \\
\hline
\end{tabular}

Conidia from the indicated strains were inoculated on coverslips and incubated at $28^{\circ}$ for $8 \mathrm{hr}$ in YGV. The modal average of the nuclear number for all strains after the initial incubation was $4(\geq 90 \%)$. After $8 \mathrm{hr}$, the coverslips were washed and shifted to either YGV or MNV-glycerol. After the shift, coverslips were processed every hour for $6 \mathrm{hr}$. Coverslips were stained with Calcofluor White and Hoechst 33258 to visualize septa and nuclei, respectively. Samples for further analysis were chosen based on the SI, which was 35-40 for all strains tested. For each strain, the length of 25 cells possessing one septum was measured and the nuclei were counted. The modal average of the nuclear number was determined for all strains, and the values represent $55-95 \%$ of the sample size. Data were subjected to the Mann-Whitney test and only the populations of A28 cells shifted to YGV and MNV-glycerol were significantly different $(\alpha=0.001)$. Lengths given represent the average and the standard error of the mean.

tion until they attain a specific cell size and complete at least one round of mitosis (HARRIs et al. 1994; WoLKow et al. 1996). Further study suggested that the timing of septum formation is controlled by the activity of the cyclin-dependent kinase NIMX ${ }^{\text {cdk1 }}$ (HARris and Kraus 1998). To gain further insight into the molecular mechanisms underlying the regulation of septum formation, we performed a genetic screen for mutants in which septation was deregulated. Here, we report that (i) the sntA1, sntB1, and sntC1 mutants display defects in the regulation of septum formation and in cell cycle checkpoint responses; (ii) the sntA 1 and sntB1 mutants affect the Tyr-15 phosphorylation state of NIMX ${ }^{\text {cdk1; }}$ and (iii) the timing of septum formation and the defects caused by the sntA 1 and sntB1 mutations can be modulated by nutrient availability.

The $s n t A$ and $s n t B$ genes are required for the regulation of septum formation and for cell cycle checkpoint responses: Previous genetic observations suggested that, in A. nidulans, predivisional hyphae are not able to form septa until they accumulate a threshold level of interphase NIMX ${ }^{\text {cdk1 }}$ activity (HARris and Kraus 1998). These observations were consistent with a model in which the Tyr15 phosphorylation state of NIMX ${ }^{\mathrm{cdk} 1}$ was maintained to prevent kinase activation until the appropriate cell size had been attained. Growth signals could conceivably cause this effect by downregulation of NIMT (the Tyr15 phosphatase) function, upregulation of ANKA (the Tyr-15 kinase) function, or both. To investigate these possibilities and identify additional components of the regulatory pathway that controls the timing of septum formation, we screened for suppressors of the Ts nimT23 mutation. Since the same pathway may also modulate cell cycle checkpoint responses (YE et al. 1996, 1997; Harris and Kraus 1998; De Souza et al. 1999; HofMANN and HARRIS 2000), we characterized the subset of suppressors that were HU hypersensitive. The suppressor mutations satisfying our criteria identified three genes: $s n t A$, sntB, and $s n t C$. It is likely that additional gene products that function in this pathway, particularly those that specifically regulate septation, could be identified by analyzing the suppressors that retain wild-type HU resistance (i.e., do not display checkpoint defects).

As predicted, the sntA1, sntB1, and sntC1 mutants display defects in the regulation of septum formation. Similar to the nimX $X^{c d 2 A F}$ mutant (HARris and KraUs 1998), predivisional hyphae possessing the sntA1, sntB1, and sntC1 mutations undergo septation at a smaller size and with fewer nuclei than wild type. Furthermore, they retain the ability to form septa despite the presence of DNA damage. An additional feature shared by the nim $X^{\text {cdc2AF }}$ mutant and the sntA1 and sntB1 mutants is abrogation of the $\mathrm{G}_{2} / \mathrm{M}$ DNA damage checkpoint (YE et al. 1997). Although other checkpoint-defective mutants can form septa in the presence of DNA damage (HARRIS and Kraus 1998; De Souza et al. 1999), they must still satisfy the cell size requirement. These observations suggest that the $s n t A$ and $s n t B$ gene products control the timing of septum formation by integrating multiple sensory inputs to regulate NIMX ${ }^{\text {cdk1 }}$ activity (Figure 8 ).

It should be noted that the checkpoint defects displayed by the sntA 1 and sntB1 mutants are not identical. Whereas the $\mathrm{G}_{2} / \mathrm{M}$ DNA damage checkpoint and the slowing of the S-phase checkpoint are dysfunctional in sntA 1 and sntB1 mutants (i.e., the replication checkpoint defect is presumably the cause of the HU hypersensitivity), only sntA 1 mutants are defective in the checkpoint that responds to loss of SEPB function. Although the basis of the latter checkpoint is not clear, these results suggest that the sntA gene product performs a global function in modulating checkpoint responses. In contrast, the $s n t B$ gene product may be required only for checkpoints that regulate mitotic entry. Alternatively, the sntB1 mutation may indirectly affect these checkpoint responses by perturbing a growth signaling pathway, as has been observed in $S$. pombe (Humphrey and ENOCH 1998).

The $s n t A$ and $s n t B$ gene products control the Tyr-15 phosphorylation state of NIMX ${ }^{\text {cdk1 }}$ : Two observations reported here suggest that the $s n t A$ and $s n t B$ gene products regulate septum formation and cell cycle checkpoint responses by influencing the Tyr-15 phosphorylation state of NIMX ${ }^{\text {cdkl }}$. First, tyrosine phosphorylation of NIMX $^{\text {cdk1 }}$ could not be detected in the sntA1 and sntB1 mutants grown under normal conditions or after exposure to a DNA-damaging agent. Second, molecular characterization of $s n t A$ demonstrates that it encodes 
A wild-type

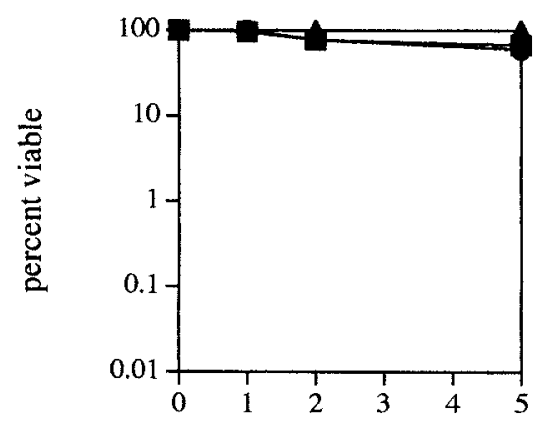

[HU] in $\mathrm{mM}$

C sntB1

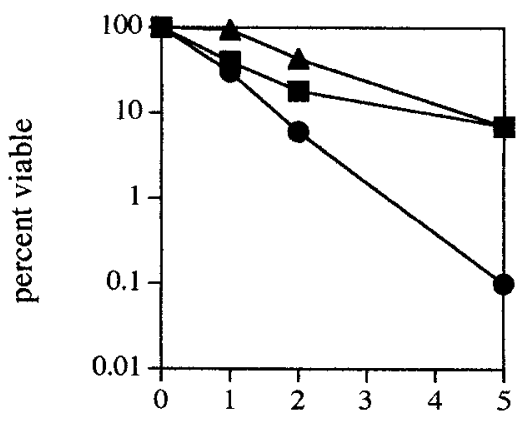

[HU] in $\mathrm{mM}$

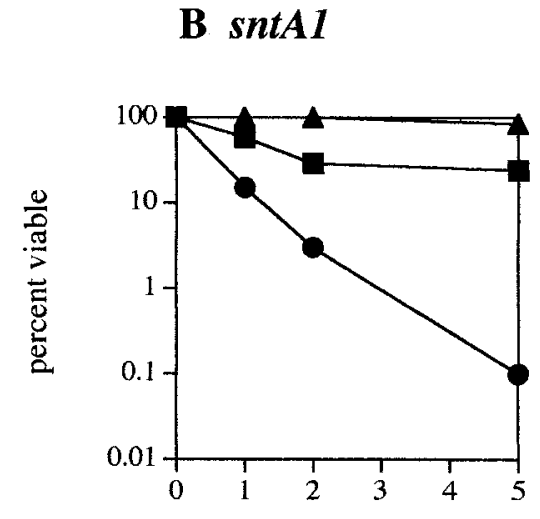

[HU] in $\mathrm{mM}$
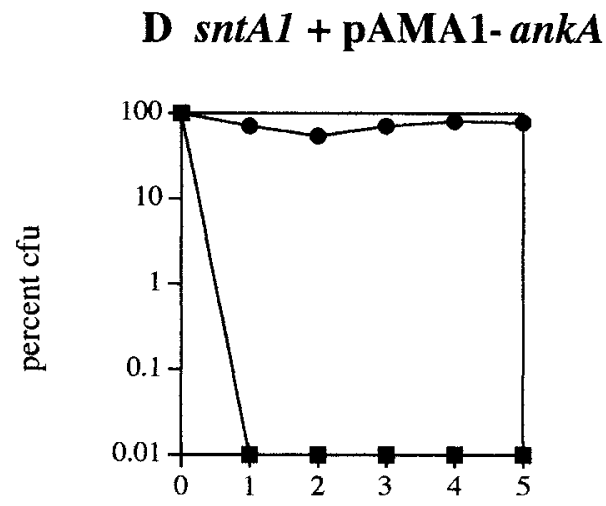

Figure 7.-Growth conditions affect the HU hypersensitivity of sntA1 and sntB1 mutants. Conidia from strains with the indicated genotype were diluted and plated at 100 conidia per plate on MNV (circles), MNV-OAc (triangles), and MNV-EtOH (squares) containing the indicated concentration of HU. The number of survivors on each plate was determined after 3 days incubation at $32^{\circ}$. "Percent viability" represents the percentage of colonies remaining on the treated plates as compared to the untreated control plates. Each data point represents the average of four plates. Experiments were repeated twice, and representative data are shown. Note that the $y$-axis for D is labeled "percent cfu," where cfu represents colony forming units. Viable colonies were observed (D) after an overlay of MNV agar lacking HU was applied and incubation continued for an additional 3 days. Strains used were the following: (A) A28, (B) APK35, (C) APK56, and (D) APK107.
ANKA, the A. nidulans ortholog of the S. pombe Tyr15 kinase Wee1p (Ye et al. 1996). Consistent with the phenotypes caused by the sntA1 mutation, ANKA has been previously shown to be required for the slowing of $\mathrm{S}$ phase and DNA damage checkpoints in A. nidulans (YE et al. 1996, 1997) and has also been implicated in the regulation of septation (DE SouzA et al. 1999). The recovery of a mutation in ANKA as a suppressor of nimT23 was not surprising, since wee1 mutations have been shown to suppress the growth defects of Tyr-15 phosphatase mutants in the yeasts $S$. pombe and $S$. cerevisiae (FAntes 1981; Booher et al. 1993). Presumably, the loss of Wee1p kinase activity restores cdk function in nimT23 mutants by lowering the overall level of Tyr-15 phosphorylation.

The ability of multiple copies of ANKA to suppress the $s n t B 1$ mutation implies that the $s n t B$ gene product also affects Tyr-15 phosphorylation of NIMX ${ }^{\text {cdk1 }}$. One possibility is that $s n t B$ encodes an upstream activator of ANKA. For example, sntB could encode a component of a signal transduction pathway that integrates growth signals with ANKA activity. Several protein kinases that negatively regulate Wee1p activity have been characterized in both $S$. pombe and S. cerevisiae (Wu and RusselL 1993; MA et al. 1996), and the $s n t B$ gene product could conceivably antagonize the function of these kinases. Alternatively, sntB could encode a protein kinase that functions in parallel with ANKA. For example, in $S$. pombe, Mik1p is a Tyr-15 kinase that appears to function redundantly with Weelp (LEE et al. 1994). If $s n t B$ does encode a Mik1p ortholog, our observations suggest that its function must have diverged to some extent from that of ANKA. In particular, the sntB1 mutation has a much greater effect on septation in a $\operatorname{sep} B 3$ background than does the sntA 1 mutation. In contrast, sntA 1 mutants display a broader spectrum of cell cycle checkpoint defects than sntB1 mutants. These observations could be explained by proposing that ANKA has a more significant role in inhibiting mitotic cdk complexes, whereas the primary function of $A$. nidulans Mik1p is to inhibit the cdk complex that controls septum formation.

The nature of the NIMX ${ }^{\text {cdk1 }}$ complex that regulates septum formation in A. nidulans remains unknown. NIME is a B-type cyclin that associates with $\mathrm{NIMX}^{\mathrm{cdk} 1}$ to control 
$\mathbf{A}$

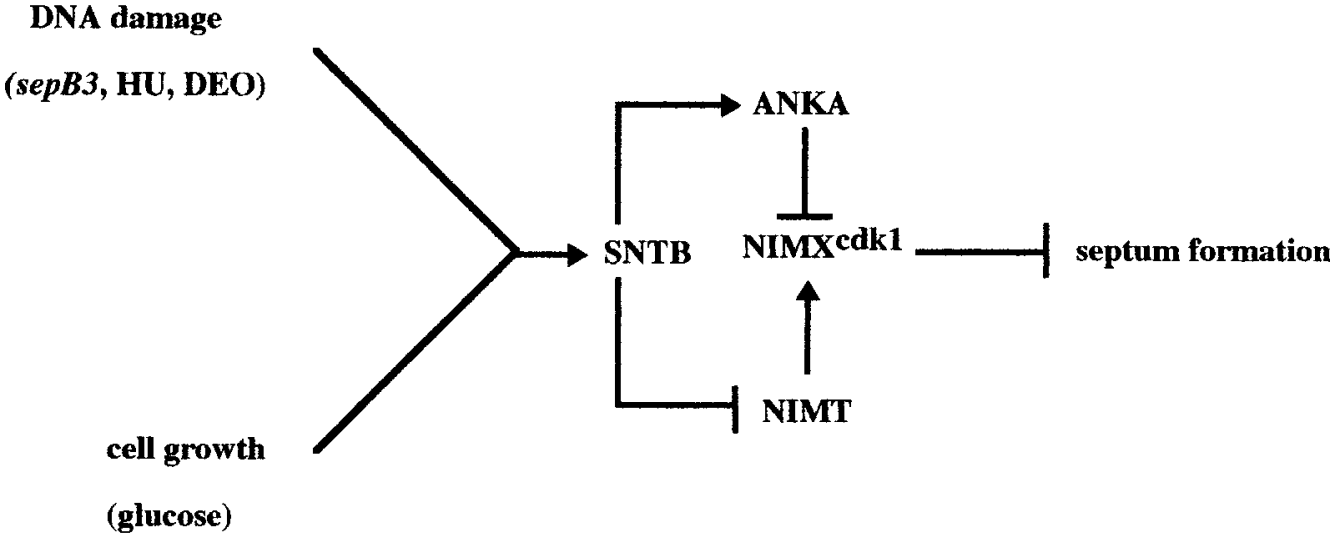

B

\section{DNA damage}

(sepB3, HU, DEO)

cell growth

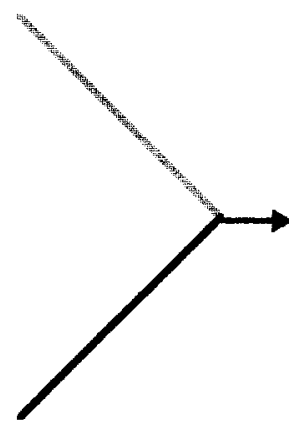

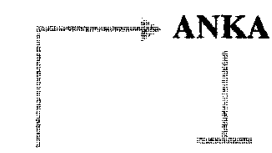

SNTB

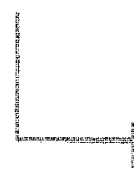

NIMX ${ }^{c d k 1}$

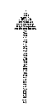

NIMT
FIGURE 8.-A branched model for the regulation of septum formation. (A) Both DNA damage and glucose influence the Tyr-15 phosphorylation state of NIMX ${ }^{\mathrm{cdk} 1}$ through the action of SNTB, which we propose modulates ANKA and NIMT (solid lines). As a result, NIMX ${ }^{\text {cdk1 }}$ activity is reduced and septum formation is delayed. (B) In the absence of glucose, the function of SNTB may be reduced (shaded lines). As a result, NIMX ${ }^{\text {cdk1 }}$ activity increases and septum formation occurs earlier with respect to cell size. Under these conditions, the ability of DNA damage to affect NIMX ${ }^{\text {cdk1 } 1}$ activity is curtailed.

(no glucose)

mitotic entry in A. nidulans (O'ConNell et al. 1992). Although the timing of septum formation is affected by the nimE6 mutation (HARRIS and KrAus 1998), we cannot rule out the existence of an additional septationspecific cyclin. If such a cyclin does exist in A. nidulans, it must be present at sufficient levels to promote septation well before predivisional hyphal cells have attained the cell size threshold. Otherwise, the sntA1, sntB1, and nim $X^{c d c 2 A F}$ mutants would not be able to septate prematurely with respect to wild-type cells. We propose that complexes between the septation cyclin and NIMX ${ }^{\text {cdk1 }}$ may be maintained in an inactive state by Tyr-15 phosphorylation. Alternatively, if there is no septation-specific cyclin, the timing of septum formation may be influenced by the localization of NIMX ${ }^{\mathrm{cdk} 1}$ (i.e., cytoplasmic $v s$. nuclear). In this case, the localization of the snt gene products may permit the mitotic cdk complex to be active while the septation complex is inhibited.

The regulation of septum formation is modulated by growth conditions: The observation that wild-type predivisional hyphae cannot septate until they attain a specific cell size suggested that the timing of septum formation is coordinated with cellular growth (WoLkow et al. 1996). We confirmed this notion by showing that predivisional hyphae shifted from rich glucose media to a poorer carbon source undergo septation at a significantly smaller size compared to hyphae that remain in glucose. We propose that septation is delayed in hyphae growing on rich glucose media so that individual hyphal cells can establish the appropriate volume of cytoplasm per nucleus. Furthermore, since the sntA1 and sntB1 mutants fail to delay septation on rich glucose media, we suggest that the $s n t A$ and $s n t B$ gene products play an active role in restraining septum formation (Figure 8). For example, glucose may activate a signal transduction pathway that inhibits activation of the relevant cdk complex by triggering the accumulation of ANKA (and/or a decrease in NIMT). In contrast, on poorer carbon sources, the relevant cdk complex may be activated by reducing the levels of ANKA (and/or the $s n t B$ 
gene product), perhaps by proteolysis (SIA et al. 1998). This would allow septation to occur at a smaller cell size compared to cells grown on glucose (Figure 8).

The relationship between cell cycle progression and cellular growth: The ability of poorer carbon sources (i.e., ethanol or acetate) to rescue the HU hypersensitivity of sntA 1 and sntB1 mutants was an unexpected observation. Moreover, suppression of $S$. pombe wee1 mutant defects by poor growth media has not been previously reported. Although minimal glucose medium has been shown to extend the $\mathrm{G}_{1}$ phase of the $A$. nidulans cell cycle (BERgen and Morris 1983), we propose that poorer carbon sources may also delay S-phase or $\mathrm{G}_{2}$ progression. Furthermore, we suggest that this delay is enacted by a mechanism that is independent of Tyr-15 phosphorylation of $\operatorname{NIMX}^{\text {cdk1 }}$ (i.e., accumulation of a cdk inhibitor). Accordingly, when exposed to HU in the presence of a poorer carbon source, activation of this mechanism may delay S-phase or $\mathrm{G}_{2}$ progression to a sufficient extent to allow the sntA1 and sntB1 mutants to respond to the lethal effects of HU. In contrast, when sntA1 mutants containing a multicopy ankA plasmid are incubated under these conditions, activation of this mechanism combined with excess ANKA may prevent colony formation by blocking mitotic entry. This idea is supported by the observation that $50 \%$ of sntA 1 cells containing the multicopy ankA plasmid fail to enter mitosis in the presence of $5 \mathrm{~mm} \mathrm{HU}$, compared to $<10 \%$ of wildtype cells (P. R. Kraus and S. D. Harris, unpublished observations).

The modulation of HU-hypersensitive phenotypes by growth conditions has been previously observed in $S$. pombe (Humphrey and EnOCH 1998). In this case, the normal response to HU was restored to a checkpointdefective mutant by inactivation of a stress-activated mitogen-activated protein kinase pathway. Our observations lend further support to the notion that regulatory mechanisms that normally act to maintain cell cycle fidelity, such as checkpoint responses, may become dispensable under adverse environmental conditions. This may have the beneficial effect of allowing the accumulation of potentially advantageous mutations.

We thank Tom Wolkow and Amy Hofmann for providing critical evaluation of the manuscript. This work was supported by awards from the University of Connecticut Health Center Research Advisory Council and the American Cancer Society (RPG-99-214-01-MBC).

\section{LITERATURE CITED}

Bergen, L. G., and N. R. Morris, 1983 Kinetics of the nuclear division cycle of Aspergillus nidulans. J. Bacteriol. 156: 155-160.

Booher, R. N., R. J. Deshaies and M. W. Kirschner, 1993 Properties of Saccharomyces cerevisiae wee 1 and its differential regulation of p34 ${ }^{\mathrm{CDC} 28}$ in response to G1 and G2 cyclins. EMBO J. 12: 3417-3426.

Cerutti, L., and V. Simanis, 2000 Controlling the end of the cell cycle. Curr. Opin. Genet. Dev. 10: 65-69.

Desany, B. A., A. A. Alcasabas, J. B. Bachant and S. J. Ellledge, 1998 Recovery from DNA replicational stress is the essential function of the S-phase checkpoint pathway. Genes Dev. 12: 29562970.

De Souza, C. P., X. S. Ye and S. A. Osmani, 1999 Checkpoint defects leading to premature mitosis also cause endoreplication of DNA in Aspergillus nidulans. Mol. Biol. Cell 10: 3661-3674.

FANTES, P. A., 1981 Isolation of cell size mutants of a fission yeast by a new selective method: characterization of mutants and implications for division control mechanisms. J. Bacteriol. 146: 746754 .

Gould, K. L., and P. Nurse, 1989 Tyrosine phosphorylation of the fission yeast $\mathrm{cdc} 2^{+}$protein kinase regulates entry into mitosis. Nature 342: 39-45.

Harris, S. D., 1997 The duplication cycle in Aspergillus nidulans. Fungal Genet. Biol. 22: 1-12.

Harris, S. D., and J. E. Hamer, 1995 sepB: an Aspergillus nidulans gene involved in chromosome segregation and the initiation of cytokinesis. EMBO J. 14: 5244-5257.

HARris, S. D., and P. R. Kraus, 1998 Regulation of septum formation in Aspergillus nidulans by a DNA damage checkpoint pathway. Genetics 148: 1055-1067.

Harris, S. D., J. L. Morrell and J. E. Hamer, 1994 Identification and characterization of Aspergillus nidulans mutants defective in cytokinesis. Genetics 136: 517-532.

Harris, S. D., L. Hamer, K. E. Sharpless and J. E. Hamer, 1997 The Aspergillus nidulans sepA gene encodes an $\mathrm{FH1} / 2$ protein involved in cytokinesis and the maintenance of cellular polarity. EMBO J. 16: 3474-3483.

Hofmann, A. F., and S. D. Harris, 2000 The Aspergillus nidulans $u v s B$ gene encodes an ATM-related kinase required for multiple facets of the DNA damage response. Genetics 154: 1577-1586.

Humphrey, T., and T. ENOCH, 1998 Sum1, a highly conserved WDrepeat protein, suppresses S-M checkpoint mutants and inhibits the osmotic stress cell cycle response in fission yeast. Genetics 148: 1731-1742.

KAfER, E., 1977 Meiotic and mitotic recombination in Aspergillus and its chromosomal aberrations. Adv. Genet. 19: 33-131.

Lee, M. S., T. Enoch and H. Piwnica-Worms, $1994 m^{2} 1^{+}$encodes a tyrosine kinase that phosphorylates $\mathrm{p} 34^{\text {dd } 2}$ on tyrosine $15 . \mathrm{J}$. Biol. Chem. 269: 30530-30537.

LEw, D. J., 2000 Cell-cycle checkpoints that ensure coordination between nuclear and cytoplasmic events in Saccharomyces cerevisiae. Curr. Opin. Genet. Dev. 10: 47-53.

Ma, X. J., Q. Lu and M. Grunstein, 1996 A search for proteins that interact genetically with histone $\mathrm{H} 3$ and $\mathrm{H} 4$ amino termini uncovers novel regulators of the Swel kinase in Saccharomyces cerevisiae. Genes Dev. 10: 1327-1340.

McGowan, C. H., and P. Russeld, 1993 Human Weel kinase inhibits cell division by phosphorylating p34 $4^{\text {cdc } 2}$ exclusively on Tyr15. EMBO J. 12: 75-85.

Millar, J. B., C. H. McGowan, G. Lenaers, R. Jones and P. Russell, $1991 \mathrm{p} 80^{d c 25}$ mitotic inducer is the tyrosine phosphatase that activates p34 ${ }^{\text {adc } 2}$ kinase in fission yeast. EMBO J. 10: 4301-4309.

Moreno, S., J. Hayles and P. Nurse, 1989 Regulation of p34 $4^{d d 2}$ protein kinase during mitosis. Cell 58: 361-372.

Neufeld, T. P., and B. A. Edgar, 1998 Connections between growth and the cell cycle. Curr. Opin. Cell Biol. 10: 784-790.

O'Connell, M. J., A. H. Osmani, N. R. Morris and S. A. Osmani, 1992 An extra copy of nimE ${ }^{\text {yddinB }}$ elevates pre-MPF levels and partially suppresses a mutation of nim $T^{\text {dd } 25}$ in Aspergillus nidulans. EMBO J. 11: 2139-2149.

Osherov, N., and G. May, 2000 Conidial germination in Aspergillus nidulans requires RAS signaling and protein synthesis. Genetics 155: $647-656$.

Osmani, A. H., S. L. McGuire and S. A. Osmani, 1991 Parallel activation of the NIMA and p34 $4^{\text {cdc } 2}$ cell cycle-regulated protein kinases is required to initiate mitosis in A. nidulans. Cell 67: 283-291.

Osmani, S. A., G. S. May and N. R. Morris, 1987 Regulation of the mRNA levels of nimA, a gene required for the G2-M transition in Aspergillus nidulans. J. Cell Biol. 104: 1495-1504.

Rhind, N., B. Furnari and P. Russell, 1997 Cdc2 tyrosine phosphorylation is required for the DNA damage checkpoint in fission yeast. Genes Dev. 11: 504-511.

Russell, P., and P. Nurse, $1986 c d c 25^{+}$functions as an inducer in the mitotic control of fission yeast. Cell 45: 145-153.

Russell, P., and P. Nurse, 1987 Negative regulation of mitosis by 
wee $1^{+}$, a gene encoding a protein kinase homolog. Cell 49: 559567.

SiA, R. A., E. S. Bardes and D. J. Lew, 1998 Control of Swelp degradation by the morphogenesis checkpoint. EMBO J. 17: $6678-6688$.

WARING, R. B., G. S. MAY and N. R. Morris, 1989 Characterization of an inducible expression system in Aspergillus nidulans using alc $A$ and tubulin-coding genes. Gene 79: 119-130.

Wolkow, T. D., S. D. HarRIS and J. E. Hamer, 1996 Cytokinesis in Aspergillus nidulans is controlled by cell size, nuclear positioning and mitosis. J. Cell Sci. 109: 2179-2188.

Wu, L., and P. Russell, 1993 Nim1 kinase promotes mitosis by inactivating Wee1 tyrosine kinase. Nature 363: 738-741.

Ye, X. S., R. R. Fincher, A. Tang, K. O’Donnell and S. A. Osmani,
1996 Two S-phase checkpoint systems, one involving the function of both BIME and Tyr 15 phosphorylation of $\mathrm{p} 34^{d c 2}$, inhibit NIMA and prevent premature mitosis. EMBO J. 15: 3599-3610.

Ye, X. S., R. R. Fincher, A. Tang and S. A. Osmani, 1997 The G2/M DNA damage checkpoint inhibits mitosis through Tyr15 phosphorylation of $\mathrm{p} 34^{\text {cdc } 2}$ in Aspergillus nidulans. EMBO J. 16: 182-192.

Zar, J. H., 1984 Biostatistical Analysis. Prentice-Hall, Englewood Cliffs, NJ.

Zeng, Y., K. C. Forbes, Z. Wu, S. Moreno, H. Piwnica-Worms et al., 1998 Replication checkpoint requires phosphorylation of the phosphatase Cdc25 by Cds1 or Chk1. Nature 395: 507-510.

Communicating editor: M. E. ZoLAN 